Yu, L., \& Huang, R. H. (2013). The influence of the scripted task on learning outcomes in collaborative learning. Journal of Educational Technology Development and Exchange, 6(1), 79-102.

\title{
The Influence of the Scripted Task on Learning Outcomes in Collaborative Learning
}

\author{
Liang Yu \\ Southwest University, China \\ Rong-Huai Huang \\ Beijing Normal University
}

\begin{abstract}
Scripting task is one of the key issues on the study of collaborative learning that primarily focuses on the influence of scripted task on learners' knowledge building. It is known that the outcomes of collaborative learning entail learners' knowledge building as well as their acquirement of collaborative skills. The paper, through a quasi-experiment, examines the effects of individual characteristics (gender and learning style), group characteristics (task type and group production), and their interaction effect on learners' knowledge acquisition and acquirement of collaborative skills. The result shows that (a) the group with the scripted task and the group with scripted task and sequence do better than the group with an unscripted task in both knowledge acquisition and collaborative skills, (b) the effect of scripted task on knowledge acquisition and collaborative skills has significant difference among students with surface approach, strategic approach and deep approach, and (c) the group with the scripted task is not significantly different from the group with scripted task and sequence on knowledge acquisition and collaborative skills. As a result, future study on scripted task is supposed to pay closer attention to its impact on learners' collaborative skills and the way to improve their collaborative skills.
\end{abstract}

Keywords: collaborative skill, knowledge acquisition, collaboration script, collaborative learning, multilevel model

\section{Introduction}

Collaborative learning is not always effective and its effects depend on the richness and intensity of interactions engaged in by group members during collaboration (Dillenbourg, 1995). Learning outcomes are related to the emergence of elaborated explanations, the negotiation of meanings, the quality of argumentation structures, and the mutual regulation of cognitive processes
(Dillenbourg \& Hong, 2008). However, when learners are left to their own devices, they hardly engage in productive interactions such as asking each other questions, explaining and justifying their opinions, articulating their reasoning, or elaborating and reflecting upon their knowledge (Barron, 2003). Collaboration scripts are activity models that aim to facilitate collaborative learning by specifying activities in collaborative settings, sequencing these activities, and assigning the activities to 
individual learners. Through specifying a sequence of learning activities, together with appropriate roles for the learners, collaboration scripts can be designed to trigger the engagement of students in learning activities that would otherwise occur rarely or not at all. Collaboration scripts can inspire students to take part in learning activities energetically, result in better knowledge building and facilitate collaborative learning (Antonio \& Jesús, 2009; Baruch, 2009; Pantelis, 2009; Rummel, 2009; Schellens, 2007; Schoonenboom, 2008; Weinberger, 2005). But, the learning objectives of collaborative learning in addition to knowledge building are of acquiring collaborative skills, which play a pivotal role in collaborative activities. If students are poor in collaborative skills such as basic social skills, the learning activity cannot be carried on. Scripting task is the main method of collaboration scripts and there are a few research studies of scripting task on knowledge building (Lockhorst, 2002; Schellens, 2007). Existing research only focus on knowledge building, one of the learning outcomes, but neglect another key learning outcome-collaborative skills. Cultivating students' collaborative skills should be the core aim of collaborative learning. At the same time, group members' possessing basic collaborative skills are the prerequisite for productive collaborative learning.

In this article, the researchers analyze the impact of scripted task on learning outcomes, namely the knowledge acquisition and collaborative skills. The value of the present study relies on that collaborative skills are introduced as one of the learning outcomes. By analyzing the effect of individual, group characteristics and their interaction effect on collaborative skills, the researchers can draw conclusions about what characteristics affect collaborative skills greatly. In this study, multilevel analysis is used to examine the influence of both individual and group characteristics.

\section{Theoretical Background}

\subsection{Literature Review}

Collaborative learning can enhance students' knowledge acquisition and improve their collaborative skills. Knowledge acquisition can be taken as the information processing activity in which new information is integrated into existing cognitive structures, building on the assumption that students engage in cognitive processing to construct mental models based on their experiences. At the same time, learners acquire collaborative skills by recalling, imitating others' collaborative actions, and reflecting on their own with regard to passed collaborative experiences. Therefore, individual pre-experiences are the basis for both knowledge acquisition and collaborative skills acquirement. Accordingly, students' individual features are considered to be of importance in collaborative learning. In addition to individual features, the group task is also an important element of affecting collaborative learning outcomes. The task triggers the cognitive process of individuals, and the structure of the task is considered to influence the depth of knowledge to be acquired and the interaction of the group. During the process of interaction, students' collaborative skills are improved.

Drawing from the literature, learners construct knowledge and acquire collaborative skills through active participation in discussing, communicating, and sharing knowledge with their peers when working in small groups on a specific assignment. But, many studies indicate that the desired learning outcomes often fail to be achieved. The participants are not actively engaged in group activities spontaneously (Graham, 1999; Hara, 2000; Salomon \& Globerson, 1989). Inactivity can be a result from features of individual students or of the tasks that they are assigned. 
Scripting is considered to enhance the communication process and can be regarded as a compromise between the freedom of collaborative learning and the constraints usually induced by instructional design (Dillenbourg \& Jermann, 2007). Scripts are activity models that aim to facilitate collaborative learning by specifying activities, sequencing these activities, and assigning the activities to individual learners (Weinberger, 2005). Also, scripts have been regarded as a qualitatively consistent possibility to facilitate collaborative learning activities (O'Donnell, 1999). The script given to students can evoke internal cognitive processes inside of them. The expected effect on the internal cognitive processes (internal script) depends on the kind of external scripts given. Learners develop and refine knowledge about how to structure their collaboration through interaction with external scripts, thereby gradually integrating procedures represented in external script into their internal scripts (Kollar, 2006). The rationale of scripts is to structure collaborative learning processes in order to trigger group interactions that may be rare in free collaboration (Dillenbourg \& Tchounikine, 2007). For Durán and Amandi (2011), these interactions depend on the collaborative skills students have and having collaborative skills is a prerequisite for learners to take part in effective collaborative learning.

The processes evoked by assigning roles and the way these processes are triggered go back to metacognitive theories. Flavell (1985) describes metacognition as that it has been broadly and rather loosely defined as knowledge or cognitive activity that takes as its object, or regulates, any aspect of any cognitive enterprise. Metacognition is the cognition about cognition. Metacognitive skills are believed to take a crucial role in many types of cognitive activities and result in learners' knowledge acquisition and the acquirement of collaborative skills. Scripting tasks in the present study can be taken as a way to stimulate metacognition.

\subsection{Research Questions}

The efficacy of collaborative learning depends on the complex interaction between these two elements: the individual features and the group task. Research about collaborative learning needs to address variables at these two levels with the aim to understand the entire story. Thereby, the present study takes into account features of individual students, as well as task characteristics. Regarding the individual features, this study focuses on the following two student characteristics: gender (Hakkarainen \& Palonen, 2003) and learning styles. As to group task characteristics, the present study focuses on the impact of the structure of task, namely scripting by assigning subtasks to students. Therefore, these two research questions are put forward:

1) How the individual features (gender and learning styles), group task types (unscripted task, scripted task, and scripted task and sequence), and their interaction affect students' knowledge acquisition?

2) How the individual features (gender and learning styles), group task types (unscripted task, scripted task, and scripted task and sequence), and their interaction affect the students' collaborative skills?

\section{Method}

\subsection{Participants}

All students enrolled for the course "Instruction Design" participated in the present study $(\mathrm{N}=93)$, and they are freshmen 
from Evening College of Beijing Normal University whose major is digital media and technology. Approximately 52 percent of the freshmen are female students, and 48 percent are male students. All of them had never studied the course and their knowledge about instruction design is not significantly different from each other.

\subsection{Hypotheses}

The study aims to explore the effect of group variables, student variables, and their interaction effect on knowledge acquisition and collaborative skills. The relationship of variables shows in Figure 1. Student variables include gender, learning style, collaborative skills, and test scores. Group variables include task type and group production scores.

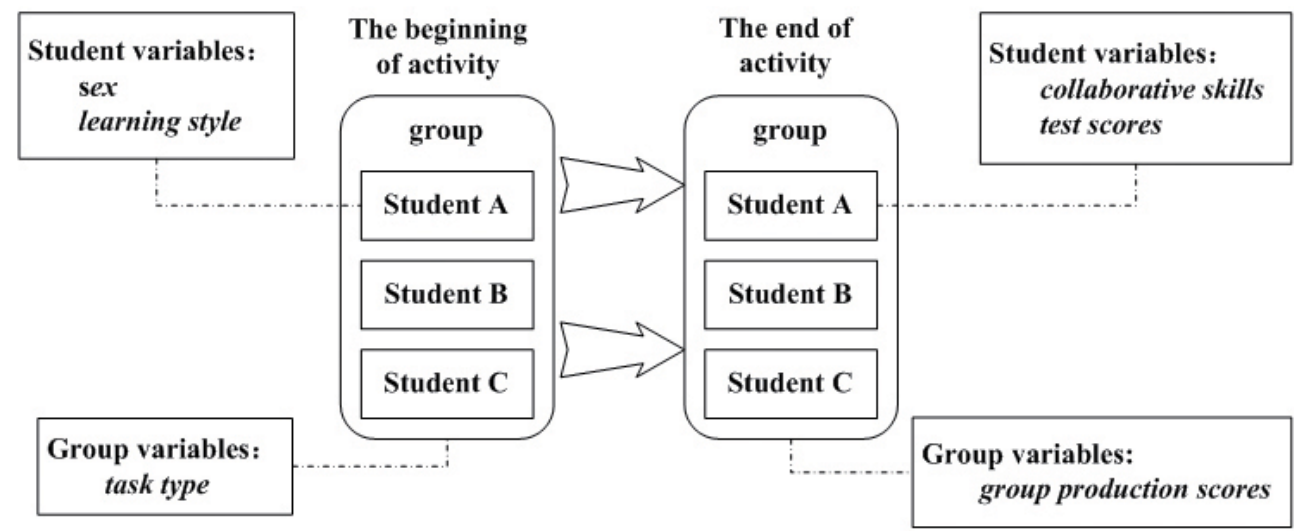

Figure 1. the Relationship of Variables

According to the relationship of variables, the study puts forward the following hypotheses.

The effect of Student variables and group variables on knowledge acquisition:

1) The group with scripted task and the group with scripted task and sequence obtain higher scores than the group with unscripted task.

2) The group with scripted task is significantly different from the group with scripted task and sequence on test scores.

3) The effect of scripted task on boys' test scores is significantly different from girls'.

4) The effect of scripted task on test scores has significant difference among students with surface approach, strategic approach and deep approach.

5) Group production scores have significant positive correlation with students' test scores.

The effect of Student variables and group variables on collaborative skills:

6) The group with scripted task and the group with scripted task and sequence obtain higher collaborative skill scores than the group with unscripted task.

7) The group with scripted task is significantly different from the group with scripted task and sequence on collaborative skills.

8) The effect of scripted task on boys' collaborative skills is significantly different from girls'. 
9) The effect of scripted task on collaborative skills has significant difference among students with surface approach, strategic approach and deep approach.

10) Group production scores and students' collaborative skill scores are significantly positively correlated with each other.

\subsection{Research Instruments}

3.3.1. Knowledge acquisition test. The test paper addresses the instructional objectives of the collaborative learning activity. It has two kinds of question items: one is true or false and the other is sorting. The true or false question is to test whether students understand the six types of questioning and the sorting question test examines if they can apply the knowledge into other situations. The test paper has eight true or false questions with eight scores aggregated and one sorting question with two scores. All students must accomplish the test in 15 minutes.

3.3.2. Collaborative skill scale. Collaborative skill scale is designed to test students' collaborative skills. This scale divided collaborative skills into three parts: communication skills, coordination skills, and collaborative attitudes. The test includes 29 statements with 6 for collaborative attitudes, 11 for communication skills, and 12 for coordination skills. The scale is a self-report instrument and students are asked to report collaborative behaviors and beliefs about collaborative skills by scoring on a five-point Likert scale from 1 (I completely disagree) to 5 (I completely agree). Reported reliability for the scale is high, with Cronbach's $\alpha$ between .71 and .74 (Yu, 2011).

\subsubsection{Learning style test scale. A short version} of the ASSIST (the Approaches and Study Skills Inventory for students) is used to test students' learning style (Tait, Entwistle, \& McCune, 1998). This short version correlates highly with the full version and can therefore be considered equivalent. The ASSIST categories learning style into three types: deep approach, strategic approach and surface approach. Table 1 shows the details about them. Cronbach's $\alpha$ for the short version are: deep approach (.76), surface approach (.72), and strategic approach (.76) (Enwistle, 2000). The short ASSIST scale consists of 18 statements. Respondents are asked to indicate on a five-point Likert scale to what extent they disagree or agree with the statements. Each of the three approaches to studying is measured by six test items. Sum-scores, based on these six items, are used in the further analysis.

Table 1. Learning Style Type

\begin{tabular}{ll}
\hline Learning style & Description \\
\hline Deep approach & $\begin{array}{l}\text { Intention to understand, relate new ideas to previous knowledge, } \\
\text { intrinsic motivation, and examine the logic of the argument. }\end{array}$ \\
$\begin{array}{l}\text { Strategic } \\
\text { approach }\end{array}$ & $\begin{array}{l}\text { Intention to obtain highest grades possible, organize time and } \\
\text { distribute effort to greatest effect, and use previous exam papers to } \\
\text { predict questions. }\end{array}$ \\
Surface approach & $\begin{array}{l}\text { Memorize information needed for assessments, treat tasks as an } \\
\text { external imposition, a focus on discrete elements without integration, } \\
\text { and a lack of direction and interest. }\end{array}$ \\
\hline
\end{tabular}




\subsection{Data Analysis Method}

This study has to deal with complex data sets that contain variables characterizing features of the groups (e.g., task type, group production scores) and variables describing the individual learners (e.g., gender, learning style) and they turn to a two- level structure. Well-established methods such as ANOVAs or linear regression models require the data sets as homogeneity of variance and independence of random errors. But, the two-level data sets do not fulfill the two requirements. Furthermore, wellestablished methods primarily deal with one level data set. If they are used to twolevel data sets, the standard error deviation will emerge that makes the reliability low. Multilevel modeling (MLM) is regarded as an alternative and adequate statistical approach to deal with the two level data sets, and it enables testing interaction effects of predictor variables varying within groups and predictors varying between groups. Taking into account the hierarchical data structure of the present study in which individuals are nested in groups, and the joint modeling of variables at different levels, the researchers adopt MLM to analyze the data. This modeling approach enables to discern variations at group and individual levels, as well as the relationship between them. The software MLwiN 2.16 (Centre for Multilevel Modelling, UK) for multilevel analysis is used to analyze the data sets. At the same time, Iterative Generalized Least Squares (IGLS) estimation procedure is applied.

\subsection{Procedure}

The quasi-experiment is conducted in the actual classroom where students are provided with the topic "question skills" — one chapter of the course. The procedure of the experiment is divided into the following four steps.
Step 1, teacher explaining: The teacher explains the basic knowledge about question skills that consists of structure, type, characteristic, and design requirements of question in 15 minutes.

Step 2, grouping randomly: Every group is made up of three students and the class is separated into 31 groups randomly. There are three types of learning tasks that are labeled as scripted task, scripted task and sequence, and unscripted task. Scripted task specifies subtasks and every group member takes on one or more subtasks. Scripted task and sequence specify not only subtasks, but also the sequence of subtasks. Group members are required to undertake subtasks and accomplish the task following the sequence. Unscripted task have no restrictions on the task and group members decide by themselves to allocate and accomplish the task. Eleven groups are assigned scripted task, another 11 groups are assigned to scripted task and sequence, and the remaining 9 groups assigned to unscripted task.

Step 3, achieving task: Every group puts the assigned task into practice and follows the rule of the task. At the end of this collaborative learning activity, group members should fill in the task table that shows the accomplishment of the work. This step lasts 90 minutes. Appendix A shows task tables for the group with scripted task, the group with scripted task and sequence, and the group with unscripted task.

Step 4, testing learning outcomes: Students take the test that reflects their acquired knowledge about "question skill" after class. At the same time, they are asked to fill out the learning style scale and the collaborative skill scale. All of these must be completed in 40 minutes. 


\section{Results}

\subsection{Multilevel Modeling about the Impact on Knowledge Acquisition Scores}

To test the hypotheses with regard to the impact on students' knowledge acquisition scores, a two-step procedure is followed. The first step in the analysis consists of the estimation of a two-level unconditional model, which partitions the variance of the dependent variable into between-groups and betweenstudents. The second step involves entering explanatory variables at the group and student level. Continuous independent variables are included to facilitate the interpretation of the intercept. Initially, all predictors are included in the model as fixed effects. Afterwards, the assumption of a fixed linear trend is verified by allowing the coefficients to vary at random. Table 2 presents the model estimating process.

The first step is to examine the results of fully unconditional two-level null model (Model 0). If student knowledge acquisition scores have no significant difference between groups, it is unnecessary to build multilevel model. The intercept 7.97 in this model represents the overall mean of knowledge acquisition scores of all students. This initial analysis entails that the estimation of the total variance of the dependent variable is 2.04 , the sum of the individual and group variance components. Individual variance is 1.46 and group variance is 0.58 . Intra-Class Correlations (ICC) is $0.58 / 2.04=0.284$. This shows that $28.4 \%$ of the overall variability in the knowledge acquisition scores can be attributed to group-level factors, and $71.6 \%$ of the variance is due to differences between individual students within group. The knowledge acquisition scores have significant difference between groups $(0.284>0.1)$. Furthermore, the random part of the null model reveals that the variance at the group level is significantly different from zero $\left(\chi^{2}=6.94, \mathrm{df}=1, \mathrm{p}<0.01\right)$. Therefore, it is indispensable to make a multilevel model.

In order to test the hypotheses, explanatory variables are included in the analysis. Because parsimonious models are preferred, only significant predictors improving the model are retained. Predictors that cannot ameliorate the model are not retained for further analysis and represented in grey in Table 2. First, the "gender" is introduced into random intercept model (model 1) as level-one explanatory variable. It is a categorical variable, represented by 'girl' as the dummy value, and contrasted against 'boy.' As can be derived from Table 2, the inclusion of the variable 'gender' induces a significant improvement of the model $0\left(\chi^{2}=8.11, \mathrm{df}=1, \mathrm{p}<0.01\right)$. Furthermore, female students do better than male students in knowledge acquisition scores $(\mathrm{Z}=0.80 / 0.28=2.86, \mathrm{p}<0.01)$. The intercept of 7.53 in Model 1 represents the overall mean score across all male students. Because the variable "gender" improves model 0 , it will be retained. To test if the variable 'gender' has significant effect on level 2 variance, the researchers allow the parameter estimate of this predictor to vary randomly across groups and students and get model $2\left(\chi^{2}=8.94, \mathrm{df}=1\right.$, $\mathrm{p}<0.01)$. It shows that this variable affects group variance significantly and various groups have different coefficients.

The next student variable "learning style" is added to the model (Model 3). Because it is also a categorical variable, two dummies are created with deep and strategic approach contrasted against the reference group with a surface study approach. Adding two dummies, Model 3 appears to significantly improve Model $2\left(\chi^{2}=12.95, \mathrm{df}=2, \mathrm{p}<0.01\right)$. Moreover, the analysis reveals significant effect for students with the deep approach $(\mathrm{Z}=1.16 / 0.31=3.74, \mathrm{p}<0.01)$ and strategic approach $(Z=0.82 / 0.30=2.73, p<0.01)$ in contrast to students with a surface approach. 
To test if the variable "learning style" has significant effect on group-level variance, the researchers allow the coefficient of the dummy (deep approach) to vary randomly across groups in the process of parameter estimating and obtain Model 4. But, this model does not significantly improve Model $3\left(\chi^{2}=0, \mathrm{df}=1\right.$, $\mathrm{p}>0.5$ ). Therefore, group variance is fixed and independent from the variable "learning style." It represents that learning style does not result in group difference of knowledge acquisition.

Table 2. Multilevel Modeling about the Impact on Knowledge Acquisition Scores

\begin{tabular}{|c|c|c|c|c|c|c|c|c|c|c|}
\hline \multicolumn{11}{|c|}{ Model } \\
\hline Parameter & $\mathbf{0}$ & 1 & 2 & 3 & 4 & 5 & 6 & 7 & 8 & 9 \\
\hline \multicolumn{11}{|l|}{ Fixed part } \\
\hline Intercept & $\begin{array}{c}7.97 \\
(0.19)\end{array}$ & $\begin{array}{c}7.53 \\
(0.23)\end{array}$ & $\begin{array}{c}7.60 \\
(0.29)\end{array}$ & $\begin{array}{c}6.71 \\
(0.35)\end{array}$ & $\begin{array}{c}6.71 \\
(0.35)\end{array}$ & $\begin{array}{c}6.37 \\
(0.85)\end{array}$ & $\begin{array}{l}5.95 \\
(0.36)\end{array}$ & $\begin{array}{c}7.52 \\
(0.39)\end{array}$ & $\begin{array}{c}6.16 \\
(0.43)\end{array}$ & $\begin{array}{c}5.53 \\
(0.37)\end{array}$ \\
\hline Gender(Female) & & $\begin{array}{c}0.80 \\
(0.28)\end{array}$ & $\begin{array}{c}0.76 \\
(0.35)\end{array}$ & $\begin{array}{c}0.82 \\
(0.32)\end{array}$ & $\begin{array}{c}0.82 \\
(0.32)\end{array}$ & $\begin{array}{c}0.81 \\
(0.33)\end{array}$ & $\begin{array}{c}0.59 \\
(0.32)\end{array}$ & $\begin{array}{c}0.59 \\
(0.32)\end{array}$ & $\begin{array}{c}0.16 \\
(0.56)\end{array}$ & $\begin{array}{c}0.55 \\
(0.30)\end{array}$ \\
\hline $\begin{array}{l}\text { Learning } \\
\text { style(Deep } \\
\text { approach) }\end{array}$ & & & & $\begin{array}{c}1.16 \\
(0.31)\end{array}$ & $\begin{array}{l}1.16 \\
(0.31)\end{array}$ & $\begin{array}{l}1.15 \\
(0.31)\end{array}$ & $\begin{array}{c}0.91 \\
(0.30)\end{array}$ & $\begin{array}{c}0.91 \\
(0.30)\end{array}$ & $\begin{array}{c}0.97 \\
(0.29)\end{array}$ & $\begin{array}{c}1.48 \\
(0.41)\end{array}$ \\
\hline $\begin{array}{l}\text { Learning } \\
\text { style(Strategic } \\
\text { approach) }\end{array}$ & & & & $\begin{array}{c}0.82 \\
(0.30)\end{array}$ & $\begin{array}{c}0.82 \\
(0.30)\end{array}$ & $\begin{array}{c}0.82 \\
(0.30)\end{array}$ & $\begin{array}{c}0.58 \\
(0.29)\end{array}$ & $\begin{array}{c}0.58 \\
(0.29)\end{array}$ & $\begin{array}{c}0.61 \\
(0.29)\end{array}$ & $\begin{array}{c}1.45 \\
(0.40)\end{array}$ \\
\hline $\begin{array}{l}\text { Group } \\
\text { production } \\
\text { scores }\end{array}$ & & & & & & $\begin{array}{c}0.05 \\
(0.11)\end{array}$ & & & & \\
\hline Scripted task & & & & & & & $\begin{array}{c}1.57 \\
(0.33)\end{array}$ & & $\begin{array}{c}0.84 \\
(0.57)\end{array}$ & $\begin{array}{c}3.31 \\
(0.57)\end{array}$ \\
\hline $\begin{array}{l}\text { Scripted task and } \\
\text { sequence }\end{array}$ & & & & & & & $\begin{array}{c}1.54 \\
(0.32)\end{array}$ & & $\begin{array}{c}1.44 \\
(0.55)\end{array}$ & $\begin{array}{c}1.77 \\
(0.62)\end{array}$ \\
\hline Unscripted task & & & & & & & & $\begin{array}{l}-1.57 \\
(0.33)\end{array}$ & & \\
\hline $\begin{array}{l}\text { Scripted task and } \\
\text { sequence }\end{array}$ & & & & & & & & $\begin{array}{l}-0.03 \\
(0.30)\end{array}$ & & \\
\hline $\begin{array}{c}\text { female* scripted } \\
\text { task }\end{array}$ & & & & & & & & & $\begin{array}{c}1.13 \\
(0.77)\end{array}$ & \\
\hline $\begin{array}{c}\text { female*scripted } \\
\text { task and } \\
\text { sequence }\end{array}$ & & & & & & & & & $\begin{array}{c}0.18 \\
(0.76)\end{array}$ & \\
\hline
\end{tabular}




\begin{tabular}{|c|c|c|c|c|c|c|c|c|c|c|}
\hline \multicolumn{11}{|c|}{ Model } \\
\hline Parameter & 0 & 1 & 2 & 3 & 4 & 5 & 6 & 7 & 8 & 9 \\
\hline $\begin{array}{l}\text { Scripted } \\
\text { task*deep } \\
\text { approach }\end{array}$ & & & & & & & & & & $\begin{array}{l}-1.97 \\
(0.66)\end{array}$ \\
\hline $\begin{array}{l}\text { Scripted task and } \\
\text { sequence*deep } \\
\text { approach }\end{array}$ & & & & & & & & & & $\begin{array}{c}-0.40 \\
(0.69)\end{array}$ \\
\hline $\begin{array}{c}\text { Scripted } \\
\text { task*strategic } \\
\text { approach }\end{array}$ & & & & & & & & & & $\begin{array}{c}-2.49 \\
(0.62)\end{array}$ \\
\hline $\begin{array}{c}\text { Scripted task } \\
\text { and sequence } \\
\text { *strategic } \\
\text { approach }\end{array}$ & & & & & & & & & & $\begin{array}{c}-0.52 \\
(0.68)\end{array}$ \\
\hline \multicolumn{11}{|l|}{ Random part } \\
\hline \multicolumn{11}{|l|}{ Level 2} \\
\hline$\sigma_{u 0}^{2}$ & $\begin{array}{c}0.58 \\
(0.29)\end{array}$ & $\begin{array}{c}0.52 \\
(0.26)\end{array}$ & & & & & & & & \\
\hline $\mathrm{u}_{0 \mathrm{j}}$ & & & $\begin{array}{c}1.42 \\
(0.57)\end{array}$ & $\begin{array}{c}1.08 \\
(0.45)\end{array}$ & $\begin{array}{c}1.08 \\
(0.45)\end{array}$ & $\begin{array}{c}1.08 \\
(0.45)\end{array}$ & $\begin{array}{c}0.92 \\
(0.40)\end{array}$ & $\begin{array}{c}0.92 \\
(0.40)\end{array}$ & $\begin{array}{c}0.83 \\
(0.37)\end{array}$ & $\begin{array}{c}0.82 \\
(0.34)\end{array}$ \\
\hline $\mathrm{u}_{1 \mathrm{j}}$ & & & $\begin{array}{c}1.98 \\
(0.97)\end{array}$ & $\begin{array}{c}1.69 \\
(0.83)\end{array}$ & $\begin{array}{c}1.69 \\
(0.83)\end{array}$ & $\begin{array}{c}1.69 \\
(0.83)\end{array}$ & $\begin{array}{c}1.89 \\
(0.80)\end{array}$ & $\begin{array}{c}1.89 \\
(0.80)\end{array}$ & $\begin{array}{c}1.61 \\
(0.73)\end{array}$ & $\begin{array}{c}1.44 \\
(0.65)\end{array}$ \\
\hline $\mathrm{u}_{2 \mathrm{j}}$ & & & & & $\begin{array}{c}0.00 \\
(0.00)\end{array}$ & & & & & \\
\hline \multicolumn{11}{|l|}{ Level1 } \\
\hline$\sigma_{\mathrm{e}}^{2}$ & $\begin{array}{c}1.46 \\
(0.26)\end{array}$ & $\begin{array}{c}1.35 \\
(0.24)\end{array}$ & $\begin{array}{c}0.82 \\
(0.18)\end{array}$ & $\begin{array}{c}0.71 \\
(0.15)\end{array}$ & $\begin{array}{c}0.71 \\
(0.15)\end{array}$ & $\begin{array}{c}0.71 \\
(0.15)\end{array}$ & $\begin{array}{c}0.68 \\
(0.15)\end{array}$ & $\begin{array}{c}0.68 \\
(0.14)\end{array}$ & $\begin{array}{c}0.67 \\
(0.14)\end{array}$ & $\begin{array}{c}0.55 \\
(0.12)\end{array}$ \\
\hline (-2*loglikelihood) & 323.87 & 315.76 & 306.82 & 293.87 & 293.87 & 293.68 & 274.11 & 274.11 & 271.69 & 258.97 \\
\hline$\chi^{2}$ & & 8.11 & 8.94 & 12.95 & 0 & 0.19 & 19.76 & 19.76 & 2.42 & 15.14 \\
\hline $\mathrm{df}$ & & 1 & 1 & 2 & 1 & 1 & 2 & 2 & 2 & 4 \\
\hline $\mathrm{p}$ & & 0.004 & 0.003 & 0.002 & 1 & 0.663 & 0.000 & 0.000 & 0.298 & 0.004 \\
\hline Reference model & & 0 & 1 & 2 & 3 & 3 & 3 & 3 & 6 & 6 \\
\hline
\end{tabular}

Note: Values in parentheses are standard errors. 
The following will test the impact of group variable on the explained variable. First, group production scores as a group variable are added to the model (Model 5). But, that does not improve Model 3 significantly $\left(\chi^{2}=0.19, \mathrm{df}=1, \mathrm{p}>0.5\right)$. Simultaneously, group production scores do not create significance on the explained variable $(\mathrm{Z}=0.05 / 0.11=0.45$, $\mathrm{p}>0.05$ ), therefore it will not be retained in the model. Second, the task type variable is added to the model (Model 6). There are three types of tasks: scripted task, scripted task and sequence, and unscripted task. These are categorical variables and two dummies are created with scripted task and scripted task and sequence contrasted against the reference group with unscripted task. From Model 6, the significant effect is observed $\left(\chi^{2}=19.76, \mathrm{df}=2\right.$, $\mathrm{p}<0.01)$. At the same time, the analysis reveals the significant effects for students with scripted task $(\mathrm{Z}=1.57 / 0.33=4.76, \mathrm{p}<0.01)$ and scripted task and sequence $(Z=1.54 / 0.32=4.81, p<0.01)$ in contrast to students with an unscripted task. Consequently, task type variable is retained in the model. In order to test whether there is a significant difference between students with scripted task and students with scripted task and sequence, two dummies are created with unscripted task and scripted task and sequence against the reference group with scripted task, and the researchers get model 7. Students with scripted task do not do better than students with scripted task and sequence $(Z=0.03 / 0.30=0.10, p>0.05)$.

Then, the interaction effect between individual level variables and group level variables is tested. First, 'female*scripted task' and 'female*scripted task and sequence' are added (model 8), and the interaction effect between 'gender' and 'task type' is tested. This analysis points out that there is no significant interaction and there is no improvement as compared to model $6\left(\chi^{2}=2.42, \mathrm{df}=2, \mathrm{p}>0.5\right)$. Second, to test interaction effect between 'task type' and 'learning style,' 'scripted task*deep approach,' 'scripted task and sequence*deep approach,' 'scripted task*strategic approach,' and 'scripted task and sequence*strategic' are added (model 9) and this model significantly improves model $6\left(\chi^{2}=15.14, \mathrm{df}=4, \mathrm{p}<0.01\right)$. This shows that scripted task has a more significant effect on students with surface approach than students with the deep approach $(Z=1.97 / 0.66=2.98, p<0.01)$ and strategic approach $(Z=2.49 / 0.62=4.02, p<0.01)$. As a result, Model 9 is the best fit model.

\subsection{Multilevel Modeling about the Impact on Collaborative Skill Scores}

To test the hypotheses regarding to the impact on collaborative skill scores, similar two-step procedures are followed. Table 3 presents the model estimating process. The first step is to examine the results of fully unconditional two-level null model (Model 0). The individual variance is 50.68 and group variance is 38.65 . The total variance of the dependent variable is 89.33 , sum of the individual and group variance components. Intra-Class Correlations (ICC) is $38.65 / 89.33=0.433$. This shows that $43.3 \%$ of the overall variability in the collaborative skill scores can be attributed to group-level factors, and another $56.7 \%$ of the variance is due to differences between individual students within group. The intercept 122.55 in this model represents the overall mean of collaborative skill scores of all students. The collaborative skill scores have significant difference between groups $(0.433>0.1)$. Furthermore, the random part of the null model reveals that the variance at group level is significantly different from zero $\left(\chi^{2}=15.81, \mathrm{df}=1, \mathrm{p}<0.01\right)$. Therefore, the result satisfies the conditions of multilevel modeling.

To test these hypotheses, explanatory variables are added to the model for the 
analysis. In order to make the model more parsimonious, only significant predictors improving the model are retained. The models not retained for further analysis are represented in grey in Table 3. First, the "gender" is introduced into random intercept model (model 1) as level-one explanatory variable. It is a categorical variable, represented by 'girl' as the dummy value, and contrasted against 'boy.' It can be derived from Table 3 that the inclusion of the variable 'gender' induces a significant improvement of model $0\left(\chi^{2}=10.88, \mathrm{df}=1\right.$, $\mathrm{p}<0.01)$. Moreover, Table 3 shows that female students significantly outperform boys on the collaborative skill scores $(Z=5.64 / 1.66=3.40$, $\mathrm{p}<0.01)$. The intercept of 119.46 in Model 1 represents the overall mean scores across all male students. Because the variable "gender" improves Model 0 significantly, it will be retained. To test if the variable "gender" has significant effect on group level variance, the researchers allow the coefficient of the dummy to vary randomly across groups and got Model $2\left(\chi^{2}=10.23, \mathrm{df}=1, \mathrm{p}<0.01\right)$. Therefore, group variance is not independent from the variable "gender." Result reveals that gender induces group difference of collaborative skill scores and Model 2 will be retained.

The variable "learning style" is added to the model (Model 3). Because it is also a categorical variable, two dummies are created with strategic and surface approach contrasted against the reference group with a deep approach. Two dummies added, Model 3 appear to significantly improve Model $2\left(\chi^{2}=16.63, \mathrm{df}=2, \mathrm{p}<0.01\right)$. Moreover, the analysis reveals significant effects for students with the strategic approach $(Z=5.56 / 1.48=3.76$, $\mathrm{p}<0.01)$ and surface approach $(Z=6.17 / 1.73=3.57, p<0.01)$ in contrast to students with deep approach. Therefore, the variable "learning style" will be retained in the model. To test if the variable "learning style" has significant effect on group level variance, the researchers allow the coefficient of the dummy (strategic approach) to vary randomly across groups and get model 4 . But, this model does not significantly improve Model 3 $\left(\chi^{2}=0, \mathrm{df}=1, \mathrm{p}>0.5\right)$. Therefore, group variance is independent from the variable "learning style." It reveals that learning style does not induce group difference of collaborative skill scores and Model 4 will not be retained.

The following tests the impact of group variable on the explained variable. First, group production scores as group variables are added to the model (Model 5). But, that does not improve Model 3 significantly $\left(\chi^{2}=0, d f=1, p>0.5\right)$. Simultaneously, group production scores do not create significance on the explained variable $(\mathrm{Z}=0.59 / 0.74=0.80$, $\mathrm{p}>0.05$ ), therefore it will not be retained in the model. Second, the task type variable is added to the model (Model 6). There are three types of tasks: scripted task, scripted task and sequence, and unscripted task. These are also categorical variables and two dummies are created with scripted task and scripted task and sequence contrasted against the reference group with unscripted task. Model 6 significantly improved Model $3\left(\chi^{2}=27.41\right.$, $\mathrm{df}=2, \mathrm{p}<0.01)$. At the same time, the analysis reveals significant effects for students with scripted task $(Z=12.58 / 1.96=6.42$, $\mathrm{p}<0.01)$ and scripted task and sequence $(\mathrm{Z}=10.39 / 1.95=5.33, \mathrm{p}<0.01)$ in contrast to students with an unscripted task. To test if there are significant differences between scripted task and scripted task and sequence, the researchers create two dummies with unscripted task and scripted task and sequence contrasted against the reference group with scripted task (model 7). But, no significant effect emerges between the groups with scripted task and the groups with scripted task and sequence $(\mathrm{Z}=2.18 / 1.94=1.12, \mathrm{p}>0.05)$. 
Table 3. Multilevel Modeling about the Impact on Collaborative Skill Scores

\begin{tabular}{|c|c|c|c|c|c|c|c|c|c|c|}
\hline \multicolumn{11}{|c|}{ Model } \\
\hline Parameter & $\mathbf{0}$ & 1 & 2 & 3 & 4 & 5 & 6 & 7 & 8 & 9 \\
\hline \multicolumn{11}{|l|}{ Fixed part } \\
\hline Intercept & $\begin{array}{l}122.55 \\
(1.34)\end{array}$ & $\begin{array}{l}119.46 \\
(1.57)\end{array}$ & $\begin{array}{l}119.52 \\
(1.69)\end{array}$ & $\begin{array}{l}116.74 \\
(1.78)\end{array}$ & $\begin{array}{l}116.74 \\
(1.78)\end{array}$ & $\begin{array}{l}112.20 \\
(5.94)\end{array}$ & $\begin{array}{l}109.44 \\
(1.57)\end{array}$ & $\begin{array}{c}122.02 \\
(1.72)\end{array}$ & $\begin{array}{l}108.91 \\
(1.71)\end{array}$ & $\begin{array}{l}106.60 \\
(1.65)\end{array}$ \\
\hline $\begin{array}{l}\text { Gender } \\
\text { (Female) }\end{array}$ & & $\begin{array}{c}5.64 \\
(1.66)\end{array}$ & $\begin{array}{c}5.77 \\
(2.13)\end{array}$ & $\begin{array}{c}4.99 \\
(2.11)\end{array}$ & $\begin{array}{c}4.99 \\
(2.11)\end{array}$ & $\begin{array}{c}4.97 \\
(2.12)\end{array}$ & $\begin{array}{c}4.23 \\
(1.86)\end{array}$ & $\begin{array}{c}4.23 \\
(1.86)\end{array}$ & $\begin{array}{c}6.11 \\
(3.05)\end{array}$ & $\begin{array}{c}4.53 \\
(1.80)\end{array}$ \\
\hline $\begin{array}{c}\text { Learning style } \\
\text { (Strategic } \\
\text { approach) }\end{array}$ & & & & $\begin{array}{c}5.56 \\
(1.48)\end{array}$ & $\begin{array}{c}5.56 \\
(1.48)\end{array}$ & $\begin{array}{c}5.68 \\
(1.48)\end{array}$ & $\begin{array}{c}5.04 \\
(1.37)\end{array}$ & $\begin{array}{c}5.04 \\
(1.37)\end{array}$ & $\begin{array}{c}5.04 \\
(1.34)\end{array}$ & $\begin{array}{l}10.02 \\
(2.20)\end{array}$ \\
\hline $\begin{array}{l}\text { Learning } \\
\text { style(Surface } \\
\text { approach) }\end{array}$ & & & & $\begin{array}{c}6.17 \\
(1.73)\end{array}$ & $\begin{array}{c}6.17 \\
(1.73)\end{array}$ & $\begin{array}{c}6.31 \\
(1.73)\end{array}$ & $\begin{array}{c}5.81 \\
(1.67)\end{array}$ & $\begin{array}{c}5.81 \\
(1.67)\end{array}$ & $\begin{array}{c}5.85 \\
(1.64)\end{array}$ & $\begin{array}{l}17.90 \\
(4.04)\end{array}$ \\
\hline $\begin{array}{l}\text { Group } \\
\text { production } \\
\text { scores }\end{array}$ & & & & & & $\begin{array}{c}0.59 \\
(0.74)\end{array}$ & & & & \\
\hline Scripted task & & & & & & & $\begin{array}{l}12.58 \\
(1.96)\end{array}$ & & $\begin{array}{l}15.33 \\
(2.37)\end{array}$ & $\begin{array}{l}18.35 \\
(2.39)\end{array}$ \\
\hline $\begin{array}{l}\text { Scripted task } \\
\text { and sequence }\end{array}$ & & & & & & & $\begin{array}{l}10.39 \\
(1.95)\end{array}$ & & $\begin{array}{c}9.11 \\
(2.36)\end{array}$ & $\begin{array}{l}13.95 \\
(2.22)\end{array}$ \\
\hline $\begin{array}{l}\text { Unscripted } \\
\text { task }\end{array}$ & & & & & & & & $\begin{array}{l}-12.58 \\
(1.96)\end{array}$ & & \\
\hline $\begin{array}{l}\text { Scripted task } \\
\text { and sequence }\end{array}$ & & & & & & & & $\begin{array}{l}-2.18 \\
(1.94)\end{array}$ & & \\
\hline $\begin{array}{c}\text { female* } \\
\text { scripted task }\end{array}$ & & & & & & & & & $\begin{array}{l}-7.71 \\
(4.15)\end{array}$ & \\
\hline $\begin{array}{c}\text { female* } \\
\text { scripted task } \\
\text { and sequence }\end{array}$ & & & & & & & & & $\begin{array}{c}2.53 \\
(4.16)\end{array}$ & \\
\hline $\begin{array}{l}\text { Scripted } \\
\text { task*strategic } \\
\text { approach }\end{array}$ & & & & & & & & & & $\begin{array}{l}-8.46 \\
(2.99)\end{array}$ \\
\hline
\end{tabular}




\begin{tabular}{|c|c|c|c|c|c|c|c|c|c|c|}
\hline \multicolumn{11}{|c|}{ Model } \\
\hline Parameter & $\mathbf{0}$ & 1 & 2 & 3 & 4 & 5 & 6 & 7 & 8 & 9 \\
\hline $\begin{array}{l}\text { Scripted task } \\
\text { and } \\
\text { sequence* } \\
\text { strategic } \\
\text { approach }\end{array}$ & & & & & & & & & & $\begin{array}{l}-7.02 \\
(3.04)\end{array}$ \\
\hline $\begin{array}{l}\text { Scripted } \\
\text { task*surface } \\
\text { approach }\end{array}$ & & & & & & & & & & $\begin{array}{l}-19.21 \\
(4.79)\end{array}$ \\
\hline $\begin{array}{c}\text { Scripted task } \\
\text { and sequence } \\
\text { *surface } \\
\text { approach }\end{array}$ & & & & & & & & & & $\begin{array}{r}-12.27 \\
(4.51)\end{array}$ \\
\hline \multicolumn{11}{|l|}{ Random part } \\
\hline \multicolumn{11}{|l|}{ Level 2} \\
\hline$\sigma_{\mathrm{u} 0}^{2}$ & $\begin{array}{c}38.65 \\
(14.43)\end{array}$ & $\begin{array}{c}36.40 \\
(13.26)\end{array}$ & & & & & & & & \\
\hline $\mathrm{u}_{0 \mathrm{j}}$ & & & $\begin{array}{c}52.23 \\
(19.89)\end{array}$ & $\begin{array}{c}51.50 \\
(18.75)\end{array}$ & $\begin{array}{c}51.48 \\
(18.77)\end{array}$ & $\begin{array}{c}53.54 \\
(19.39)\end{array}$ & $\begin{array}{l}13.10 \\
(7.46)\end{array}$ & $\begin{array}{l}13.10 \\
(7.46)\end{array}$ & $\begin{array}{l}10.40 \\
(6.66)\end{array}$ & $\begin{array}{l}14.38 \\
(6.85)\end{array}$ \\
\hline $\mathrm{u}_{1 \mathrm{j}}$ & & & $\begin{array}{l}75.60 \\
(34.73)\end{array}$ & $\begin{array}{c}80.48 \\
(33.52)\end{array}$ & $\begin{array}{c}80.64 \\
(33.43)\end{array}$ & $\begin{array}{c}82.25 \\
(33.79)\end{array}$ & $\begin{array}{c}69.11 \\
(27.16)\end{array}$ & $\begin{array}{c}69.11 \\
(27.16)\end{array}$ & $\begin{array}{c}49.26 \\
(22.16)\end{array}$ & $\begin{array}{c}69.84 \\
(25.16)\end{array}$ \\
\hline $\mathrm{u}_{2 \mathrm{j}}$ & & & & & $\begin{array}{c}0.00 \\
(0.00)\end{array}$ & & & & & \\
\hline \multicolumn{11}{|l|}{ Level1 } \\
\hline$\sigma_{\mathrm{e}}^{2}$ & $\begin{array}{l}50.68 \\
(9.10)\end{array}$ & $\begin{array}{l}44.30 \\
(7.96)\end{array}$ & $\begin{array}{l}24.41 \\
(5.30)\end{array}$ & $\begin{array}{l}19.27 \\
(4.19)\end{array}$ & $\begin{array}{l}19.27 \\
(4.19)\end{array}$ & $\begin{array}{l}19.27 \\
(4.20)\end{array}$ & $\begin{array}{l}19.16 \\
(4.14)\end{array}$ & $\begin{array}{l}19.16 \\
(4.14)\end{array}$ & $\begin{array}{l}19.23 \\
(4.16)\end{array}$ & $\begin{array}{l}13.75 \\
(2.99)\end{array}$ \\
\hline $\begin{array}{c}\left(-2^{*}\right. \\
\text { loglikelihood) }\end{array}$ & 665.89 & 655.01 & 644.78 & 628.15 & 628.15 & 627.58 & 600.74 & 600.74 & 594.40 & 581.99 \\
\hline$\chi^{2}$ & & 10.88 & 10.23 & 16.63 & 0 & 0.57 & 27.41 & 27.41 & 6.34 & 18.75 \\
\hline $\mathrm{df}$ & & 1 & 1 & 2 & 1 & 1 & 2 & 2 & 2 & 4 \\
\hline $\mathrm{p}$ & & 0.001 & 0.001 & 0.000 & 1.000 & 0.450 & 0.000 & 0.000 & 0.042 & 0.001 \\
\hline $\begin{array}{c}\text { Reference } \\
\text { model }\end{array}$ & & 0 & 1 & 2 & 3 & 3 & 3 & 3 & 6 & 6 \\
\hline
\end{tabular}

Note: Values in parentheses are standard errors. 
In the end, the interaction effect between individual level variables and group level variables is tested. First, to test the crosslevel interaction effect between the variable "gender" and the variable "task type," 'female*scripted task' and 'female*scripted task and sequence' are added to the model (Model 8) that significantly improve Model $6\left(\chi^{2}=6.34, \mathrm{df}=2, \mathrm{p}<0.05\right)$. But, the effect of scripted task $(Z=7.71 / 4.15=1.86, p>0.05)$, as well as scripted task and sequence $(Z=2.53 / 4.16=0.61, p>0.05)$ on female students, is not significantly different from male students. Second, to test interaction effect between 'task type' and 'learning style,' 'scripted task*strategic approach,' 'scripted task and sequence*strategic approach,' 'scripted task*surface approach,' and 'scripted task and sequence*surface approach' are added (model 9) and this model significantly improves model $6\left(\chi^{2}=18.74, \mathrm{df}=4, \mathrm{p}<0.01\right)$. It shows that scripted task produces a significant effect on students with deep approach than students with strategic approach $(Z=8.46 / 2.99=2.83, p<0.01)$ and surface approach $(Z=19.21 / 4.79=4.01, p<0.01)$. At the same time, scripted task and sequence also creates a more significant effect on students with deep approach than students with strategic approach $(Z=7.02 / 3.04=2.31, p<0.05)$ and surface approach $(Z=12.27 / 4.51=2.72$, $\mathrm{p}<0.01)$. Further analysis does not show that the explanatory variable has obvious impact within group variance. As a result, Model 9 is the best fit model.

\section{Discussion}

\subsection{The Influence of the Scripted Task on Knowledge Acquisition}

The article, through multilevel modeling, explores the influence of both the individual and group traits on knowledge acquisition and consequently some related hypotheses are examined in that way.
Hypothesis 1: The group with scripted task and the group with scripted task and sequence obtain higher scores than the group with unscripted task.

The group with scripted task specifies subtasks and every group member takes on one or more subtasks. The group with scripted task and sequence specifies not only subtasks, but also the sequence of subtasks. Group members should undertake subtasks and accomplish the task by following a sequence. Consequently, the structured degree of the collaborative activities in the group with scripted task and sequence is higher than the group with the scripted task, and students in the group with scripted task and sequence are more inclined to participate in the collaborative learning activities to accomplish the tasks. Table 2 shows the scores of both the group with scripted task $(Z=1.57 / 0.33=4.76, p<0.01)$ and the group with scripted task and sequence $(Z=1.54 / 0.32=4.81, p<0.01)$ are higher than the unscripted group, so this hypothesis can be accepted. It is implied that the method of scripted task or scripted task and sequence can improve students' knowledge acquisition. Therefore, it is effective to implement the scripted task and scripted task and sequence in the design of collaborative learning to help students master the fundamental knowledge. Nevertheless, the research on the methods concerning how task and sequence are scripted in the collaborative learning activities is always a hot issue with the goal of helping students with low level of collaborative skills to successfully perform collaborative learning. Some scholars endeavor to make some explorations in this field. Lockhorst (2002) believes that task instruction, one way of task script, is the key step to perform effectively collaborative learning activities, and particularly, significant in the asynchronous collaborative activities. She advocates that more attention be paid to the issue on 
scripting task, rather than the results of CSCL (Computer Supported Collaborative Learning) and students' cognitive learning process. Besides, Schellens (2004) points out that for the theme discussion among collaborative group members, the distinct scripted task motivates task-oriented communication, and thus, facilitates learners to achieve the goal of knowledge building. These research studies verify that scripted task and knowledge building has positive correlation.

Hypothesis 2: The group with scripted task is significantly different from the group with scripted task and sequence on test scores.

As can be seen from Table 2, the effect of scripted task on students' test scores is not significantly different from scripted task and sequence $(Z=0.03 / 0.30=0.10, p>0.05)$. This hypothesis must be rejected. It does not mean that the structure of collaborative learning is denser, but that students do better in knowledge acquisition.

Hypothesis 3: The effect of scripted task on boys' test scores is significantly different from girls'.

Female students obtain higher test scores than male students $(\mathrm{Z}=0.80 / 0.28=2.86$, $\mathrm{p}<0.01)$. But, the effect of scripted task on boys' test scores is not significantly different from girls' $(Z=1.13 / 0.77=1.47, p>0.05)$. Consequently, this hypothesis is rejected. This illustrates that scripted task does not create a different effect between boys' and girls' knowledge acquisition.

Hypothesis 4: The effect of scripted task on test scores has significant difference among students with surface approach, strategic approach and deep approach.

According to Table 2, both the deep approach students $(Z=1.16 / 0.31=3.74$, $\mathrm{p}<0.01)$ and strategic approach students $(\mathrm{Z}=0.82 / 0.30=2.73, \mathrm{p}<0.01)$ obviously achieve higher scores in the test than the surface approach students. This conclusion is in coincidence with the previous research outcomes. For instance, Duff (2004) concludes through an experimental study that deep approach students and strategic approach students are more likely to achieve higher marks, than the surface approach students. Furthermore, Schellens (2004) points out that when students are required to perform collaborative learning activities in asynchronous discussions, the deep approach students do a better job than those surface approach students in the final examination. However, scripted task has more significant effect on students with the surface approach than students with deep approach $(\mathrm{Z}=1.97 / 0.66=2.98, \mathrm{p}<0.01)$ and strategic approach $(Z=2.49 / 0.62=4.02, p<0.01)$. This hypothesis is accepted.

Hypothesis 5: Group production scores have significant positive correlation with students'test scores.

Group production scores has no significant effect on students' test scores $(\mathrm{Z}=0.05 / 0.11=0.45, \mathrm{p}>0.05)$. Meanwhile, the Pearson coefficient is obtained that $\mathrm{r}=0.098, \mathrm{p}=0.351$, by analyzing the correlation between the group production scores and students' test scores in SPSS 17.0. This shows Group production scores is not significantly correlated with students' test scores, and the hypothesis is rejected.

The influence of the scripted task on collaborative skills

Through multilevel modeling, the influence of both the individual and group traits on collaborative skills is explored and the related hypotheses are checked based on that. 
Hypothesis 6: The group with scripted task and the group with scripted task and sequence obtain higher collaborative skill scores than the group with unscripted task.

Both the group with the scripted task $(\mathrm{Z}=12.58 / 1.96=6.42, \mathrm{p}<0.01)$ and the group with scripted task and sequence $(\mathrm{Z}=10.39 / 1.95=5.33, \mathrm{p}<0.01)$ outperform the group with unscripted task in collaborative skill scores. Hence, the hypothesis is accepted. In the collaborative learning activities, when group members interact with each other, they learn from each other attitudes, values, techniques and useful information, appreciate others' desirable capabilities and imitate them. The group members ultimately form different behaviors, attitudes, and views by means of learning from the models, reinforcement, and direct study. Furthermore, only by interacting with each other, can group members behave in the way of helping, comforting, sharing, understanding, conflict resolving and devoting, and can they feel the sense of identity, acceptance, support, and caring. This is based on group members continuing to exercise and sustain the collaborative skills that are essential for their interdependent relationships. Johnson (1979) supposes that group members, through the collaborative experience, are able to develop a social sensitivity to perceive the behaviors expected by others and obtain an idea of the practical skills and independence needed to meet those expectations.

Group members in the collaborative activities are responsible for their social behaviors and in this way have great influence on their internalized values and developed self-discipline. By inter-depending on each other, group members learn certain values and internalize them. It is in the way of interacting with one other that group members develop social competences like believing in others, inspecting issues in a comprehensive view, realizing the goal of life and the meaningfulness of it, and self-identity. As a result, learners' collaborative skills can only be cultivated in the practical collaborative activities.

Learners can acquire collaborative skills only in the way of participating in collaborative learning activities. It is concluded that learners in the group with scripted task and the group with scripted task and sequence perform the collaborative activities at a higher level than those in the group with unscripted task, and the former are more likely to take part in and accomplish collaborative learning tasks, in which students learn more easily, set up constructive partnerships, and improve collaborative skills. The lower structure of the collaborative learning activity requires group members to make more effort. If the collaborative task is too difficult, the new group members are likely to have a sense of failure and anxiety, and retreat from the activities that will result in the negative atmosphere and tension within the group. Finally, group members will fail to finish the learning tasks. Therefore, scripting collaborative learning task is suggested especially when significant to those who have not been involved in the collaborative learning activities before. Accepting the hypothesis means scripted task or scripted task and sequence help to improve learners' collaborative skills.

Hypothesis 7: The group with scripted task is significantly different from the group with scripted task and sequence on collaborative skills.

There is no significant difference in scores of the collaborative skills between the deep approach students and the surface approach students $(Z=2.18 / 1.94=1.12$, $\mathrm{p}>0.05$ ). Therefore, the hypothesis is rejected. Consequently, it is concluded that the scripting of the collaborative learning task facilitates group members to improve their collaborative 
skills, but the higher degree of structure does not intend the more advanced level of the collaborative skills.

Hypothesis 8: The effect of scripted task on boys' collaborative skills is significantly different from girls'.

As can be seen from Table 3, the variable "gender" improved significantly for Model 0 $\left(\chi^{2}=10.88, \mathrm{df}=1, \mathrm{p}<0.01\right)$. Girls' collaborative skill scores are apparently higher than boys' $(\mathrm{Z}=5.64 / 1.66=3.40, \mathrm{p}<0.01)$. Some researchers have performed studies on the differences between boys' and girls' collaborative skills. For example, Nevgi, Virtanen, and Niemi (2006) utilize the tool of IQ Team to support adult learners' acquiring collaborative skills. They did two sample experiments in which one sample numbers 259 , and the other 275 , in order to test the online learners' different performances on collaborative skills in different groups. The results show that boys $(\mathrm{M}=3.10)$ are clearly more likely to take control than girls $(\mathrm{M}=2.83, \mathrm{t}=2271$, $\mathrm{df}=211, \mathrm{p}<0.024)$, while girls $(\mathrm{M}=4.22)$ are more inclined to share experiences with each other than boys $(M=4.01, t=-2252$, $\mathrm{df}=211, \mathrm{p}<0.025)$. The desire for controlling takes a negative effect on the acquisition of collaborative skills, while the desire for sharing is a component of collaborative skills. As a result, it is proved in the above research that girls do a better job than boys in the performance of collaborative skills.

Nevertheless, Table 3 shows that the effect of scripted task on boys' collaborative skills is not significantly different from girls' $(Z=7.71 / 4.15=1.86, p>0.05)$. Therefore, the hypothesis is rejected.

Hypothesis 9: The effect of scripted task on collaborative skills has significant difference among students with surface approach, strategic approach and deep approach.
As can be seen from Table 3, students with strategic approach $(Z=5.56 / 1.48=3.76, p<0.01)$ and surface approach $(Z=6.17 / 1.73=3.57$, $\mathrm{p}<0.01)$ do better than students with deep approach in collaborative skill scores. But, the effect of scripted task on students with deep approach is stronger than students with strategic approach $(\mathrm{Z}=8.46 / 2.99=2.83, \mathrm{p}<0.01)$ and surface approach $(Z=19.21 / 4.79=4.01$, $\mathrm{p}<0.01)$. At the same time, the effect of scripted task and sequence on students with deep approach is also stronger than students with strategic approach $(\mathrm{Z}=7.02 / 3.04=2.31$, $\mathrm{p}<0.05$ ) and surface approach $(\mathrm{Z}=12.27 / 4.51=2.72, \mathrm{p}<0.01)$. Accordingly, the hypothesis is accepted.

Hypothesis 10: Group production scores and students' collaborative skill scores are significantly positively correlated with each other.

It is concluded that the group production scores do not significantly affect students' collaborative skill scores $(\mathrm{Z}=0.59 / 0.74=0.80$, $\mathrm{p}>0.05$ ). The Pearson coefficient is obtained $(\mathrm{r}=0.018, \mathrm{p}=0.865)$ after the correlation analysis is made between the group production scores and the testing scores of students' collaborative skills by means of SPSS 17.0. The results show that there is no significant correlation between the two, therefore the hypothesis is rejected.

\section{Conclusions, Limitations, and Future Work}

By conducting a quasi-experiment in an actual classroom and applying multilevel modeling method into analyzing the data set from the experiment, this study addresses the impact of the individual characteristics (e.g., gender and learning style), group characteristics (e.g., group production scores, task type), and their interaction effect on students' knowledge acquisition and 
collaborative skills. Three key conclusions can be drawn: (1) the group with the scripted task and the group with scripted task and sequence do better than the group with the unscripted task in both knowledge acquisition and collaborative skills, (2) the effect of scripted task on test scores and collaborative skills has a significant difference among students with surface approach, strategic approach, and deep approach, and (3) the group with scripted task is not significantly different from the group with scripted task and sequence on test scores and collaborative skill scores. Therefore, learning style is the key variable for knowledge acquisition and collaborative learning that deserves more attention in the process of designing collaborative learning. Scripting task can improve students, collaborative skills, but it does not mean that greater the script is structured the more students' collaborative skills will be enhanced. In order to facilitate the cultivation of collaborative skills for students, it is important for the researchers to pay close attention to the impact of scripting task on collaborative skills except for knowledge building.

Due to several limitations, the present study may be criticized. First, the quasiexperiment was conducted in two hours and the sample was only 93 participants; results can be questioned whether the findings can be generalized to students in other domains and to knowledge that may have been acquired before. Second, the question could be raised why the relationship between the different learning outcomes (e.g., knowledge acquisition and collaborative sills) was not investigated by exploring causal paths. Further study should introduce the combination of both multilevel and structural equation modeling techniques. Third, a comment could be made on the fact that besides student characteristics of gender and learning styles are investigated in this study, the findings are missing other student characteristics such as age and intelligence. Within practical scope, the researchers could not examine all of the characteristics and moreover, the researchers especially focus on the variables that could be manipulated in the actual classroom.

Future work should focus on larger sample sizes and a wider range of higher education students to obtain a better understanding of the impact of both individual and group characteristics on knowledge acquisition and collaborative skills. At the same time, the empirical study about how scripting task can take effect on students' collaborative skills should be conducted in various subjects in college classes. More attention should be paid to facilitating the enhancement of the collaborative skills in collaborative learning research.

\section{References}

Anaya, A. R., \& Boticario, J. G. (2009). Reveal the collaboration in an open learning environment. In J. Mira, J. M. Ferrández, J. R. Alvarez, F. Paz, \& J. Toledo (Eds.), Methods and models in artificial and natural computation. A homage to Professor Mira's scientific legacy (pp. 464-475). Heidelberg, Berlin: Springer.

Barron, B. (2003). When smart groups fail. The Journal of the Learning Sciences, 12(3), 307-359.

Dillenbourg, P., Baker, M. J., Blaye, A., \& O'Malley, C. (1995). The evolution of research on collaborative learning. In E. Spada \& P. Reiman (Eds.), Learning in humans and machine: Towards an interdisciplinary learning science (pp. 189-211), Oxford: Elsevier.

Dillenbourg, P., \& Hong, F. (2008). The mechanics of CSCL macro scripts. International Journal of ComputerSupported Collaborative Learning, 3(1), 
$5-23$.

Dillenbourg, P., \& Jermann, P. (2007). Designing integrative scripts. In F. Fischer, I. Kollar, H. Mandl, \& M. HaakeJörg. Scripting computer-supported collaborative learning (pp. 275-301). Boston, MA: Springer.

Dillenbourg, P., \& Tchounikine, P. (2007). Flexibility in macro-scripts for computer supported collaborative learning. Journal of Computer Assisted Learning, 23(1), 1-13.Duff, A., Boyle, E., Dunleavy, K., \& Ferguson, J. (2004). The relationship between personality, approach to learning and academic performance. Personality and Individual Differences, 36(8), 1907-1920.

Durán, E. B., \& Amandi, A. (2011). Personalised collaborative skills for student models. Interactive Learning Environments, 19(2), 143-162.

Flavell, J. H., Miller, P. H., \& Miller, S. A. (1985). Cognitive development. Englewood Cliffs, NJ: Prentice-Hall.

Graham, M., Scarborough, H., \& Goodwin, C. (1999). Implementing computer mediated communication in an undergraduate course: A practical experience. Journal of Asynchronous Learning Networks, 3(1), 32-45.

Hakkarainen, K., \& Palonen, T. (2003). Patterns of female and male students' participation in peer interaction in computer-supported learning. Computers \& Education, 40(4), 327-342.

Hara, N., Bonk, C. J., \& Angeli, C. (2000). Content analysis of online discussion in an applied educational psychology course. Instructional Science, 28(2), 115-152.

Johnson, D. W., \& Johnson, R. T. (1979). Conflict in the classroom: Controversy and learning. Review of Educational Research, 49(1), 51-69.

Kollar, I., Fischer, F., \& Hesse, F. W. (2006). Collaboration scripts-A conceptual analysis. Educational Psychology Review, 18(2), 159-185.

Lockhorst, D., Admiraal, W., Pilot, A., \& Veen, W. (2002). Design elements for a CSCL environment in a teacher training programme. Education and Information Technologies, 7(4), 377-384.

Nevgi, A., Virtanen, P., \& Niemi, H. (2006). Supporting students to develop collaborative learning skills in technologybased environments. British Journal of Educational Technology, 37(6), 937-947.

O’Donnell, A. M. (1999). Structuring dyadic interaction through scripted cooperation. In A. M. O'Donnell \& A. King (Eds.), Cognitive perspectives on peer learning (pp. 179-196). Mahwah, NJ: Lawrence Erlbaum.

Papadopoulos, P. M., Demetriadis, S. N., \& Stamelos, I. G. (2009). Analyzing the role of students' self-organization in a case of scripted collaboration. In C. O'Malley, D. Suthers, P. Reimann, \& A. Dimitracopoulou (Eds.), Computer Supported Collaborative Learning Practices: CSCL 2009 Conference Proceedings (pp. 487-496). Rhodes, Greece: International Society of the Learning Sciences.

Rummel, N., Spada, H., \& Hauser, S. (2009). Learning to collaborate while being scripted or by observing a model. International Journal of ComputerSupported Collaborative Learning, 4(1), 69-92.

Salomon, G., \& Globerson, T. (1989). When teams do not function the way they ought to. International Journal of Educational Research, 13(1), 89-99.

Scardamalia, M., \& Bereiter, C. (1994). Computer support for knowledge-building communities. The Journal of the Learning Sciences, 3(3), 265-283.

Schellens, T. (2004). Studying in a blended learning environment: Researching 
congruency between learning environment and student characteristics and the impact of CSCL on knowledge construction (Unpublished doctoral dissertation). Ghent University, Ghent.

Schellens, T., Van Keer, H., De Wever, B., \& Valcke, M. (2007). Scripting by assigning roles: Does it improve knowledge construction in asynchronous discussion groups? International Journal of Computer-Supported Collaborative Learning, 2(2-3), 225-246.

Schoonenboom, J. (2008). The effect of a script and a structured interface in grounding discussions. International Journal of Computer-Supported Collaborative Learning, 3(3), 327-341.

Schwarz, B. B., Asterhan, C. S., \& Gil, J. (2009). Human guidance of synchronous e-discussions: The effects of different moderation scripts on peer argumentation. In C. O'Malley, D. Suthers, P. Reimann, \& A. Dimitracopoulou (Eds.), Computer Supported Collaborative Learning Practices: CSCL 2009 Conference Proceedings (pp. 497-506). Rhodes, Greece: International Society of the Learning Sciences.

Tait, H., Entwistle, N. J., \& McCune, V. (1998). ASSIST: A reconceptualisation of the approaches to studying inventory. In $\mathrm{C}$. Rust (Ed.), Improving students as learners (pp. 262-271). Oxford: Oxford Brookes University.

Weinberger, A., Ertl, B., Fischer, F., \& Mandl, H. (2005). Epistemic and social scripts in computer-supported collaborative learning. Instructional Science, 33(1), $1-30$.

Yu, L. (2011). Facilitating the cultivation of collaborative skills with collaboration script (Unpublished doctoral dissertation). Beijing Normal University, Beijing.

\section{Acknowledgements}

This work was supported in part by Humanity and Social Science Research Youth foundation of Ministry of Education of China under Grant No. 11YJCZH220, the Fundamental Research Funds for the Central Universities under Grant No. XDJK2012C024, and the Doctoral Fund of Southwest University under Grant No. SWU1110361. The opinions, findings, and conclusions do not reflect the views of the funding agencies, cooperating institutions, or other individuals.

\section{Contact the Authors}

\section{Liang $\mathrm{Yu}$}

Southwest University

Email: toliangyu@gmail.com

\section{Rong-Huai Huang}

Beijing Normal University

Email: huangrh@bnu.edu.cn 


\section{Appendix A}

\section{The Group with Scripted Task}

Please read the text "Infection and Immunity" (it is chosen from Biology textbook for grade eight in K12 with People's Education Press version). Then each of three students is assigned two questions - one is from Number 1 to Number 3 and the other from Number 4 to Number 6 . After completing the design of six questions respectively, make the appropriate order of them collaboratively and fill in Table 1 and Table 2.

Table 1. The Design of Question

\begin{tabular}{|c|c|c|c|}
\hline Number & Type & Question & Designer \\
\hline 1 & Recollection & & \\
\hline 2 & Comprehension & & \\
\hline 3 & Application & & \\
\hline 4 & Analysis & & \\
\hline 5 & Synthesis & & \\
\hline 6 & Evaluation & & \\
\hline
\end{tabular}


Table 2. The Order of Questions

\section{The Group with Scripted Task and Sequence}

Please read the text "Infection and Immunity" (it is chosen from Biology textbook for grade eight in K12 with People's Education Press version). Then each of three students is assigned two questions - one is from Number 1 to Number 3 and the other from Number 4 to Number 6. Compared to the group with scripted task, this group introduces an inspection procedure and steps of which are the following: student B inspect student A's questions and give some advices, and student $\mathrm{A}$ can make modifications; in this way, student $\mathrm{C}$ inspect student $\mathrm{B}$ and student $\mathrm{A}$ inspect C. After completing the design of six questions respectively, make the appropriate order of them collaboratively and fill in Table 3 and Table 4.

Table 3. The Design of Question

\begin{tabular}{|c|c|c|c|c|}
\hline Number & Type & Question & Designer & Inspector \\
\hline 1 & Recollection & & & \\
\hline 2 & Comprehension & & & \\
\hline 3 & Application & & & \\
\hline 4 & Analysis & & & \\
\hline & & & & \\
\hline
\end{tabular}




\begin{tabular}{|c|c|l|l|l|}
\hline 5 & Synthesis & & & \\
\hline 6 & Evaluation & & & \\
\hline
\end{tabular}

Table 4. The Order of Questions

\section{The Group with Unscripted Task}

Please read the text "Infection and Immunity" (it is chosen from Biology textbook for grade eight in K12 with People's Education Press version). Then complete the design of six questions, make the appropriate order of them and fill in Table 5 and Table 6 collaboratively.

Table 5. The Design of Question

\begin{tabular}{|c|c|c|c|}
\hline Number & Type & Question & Designer \\
\hline 1 & Recollection & & \\
\hline 2 & Comprehension & & \\
\hline 3 & Application & & \\
\hline
\end{tabular}




\begin{tabular}{|c|l|l|l|}
\hline 4 & Analysis & & \\
\hline 5 & Synthesis & & \\
\hline 6 & Evaluation & & \\
\hline
\end{tabular}

Table 6. The Order of Questions 